\title{
Design, Dirt and Disposal: Influences on the maintenance of vacuum cleaners
}

\author{
L. Harmer ${ }^{\text {a, * }}$, T. Cooper, T. Fisher c, G. Salvia b' d, C. Barr ${ }^{\text {a }}$
}

${ }^{a}$ Loughborough Design School, Loughborough University, Loughbourgh, UK

Trent University, Nottingham, UK

${ }^{c}$ School of Art and Design, Nottingham Trent University, Nottingham, UK

d Dept. of Architecture and Urban Studies, Politecnico di Milano, Milan, Italy

\section{A R T I C LE IN F O}

\section{Article history:}

Received 7 August 2018

Received in revised form 29 March 2019

Accepted 9 April 2019

Available online $\mathrm{xxx}$

Keywords:

user experience

Product longevity

Vacuum cleaners

Cleanlines

Hygiene

Dirt

Maintenance

\section{A B S T R A C T}

This paper explores the relationship between people's feelings about dirt, and an apparent reduction in the lifetime of vacuum cleaners. The short life-spans of acuum cleaners is a significant environmental issue. In addition to the waste generated, they have an impact on climate change: vacuum cleaners account for the second largest embodied greenhouse gas emissions of electrical goods in the UK after televisions, largely because of their high sales volumes.

Drawing from qualitative and quantitative research undertaken for the UK Department for Environment, Food \& Rural Affairs (Defra), the paper demonstrates that one motivation for vacuum cleaner replacement is the increased enjoyment from dirt remoyal that a new yacuum cleaner may provide. The paper also shows that premature disposal can occur once a product becomes dirty and visually damaged, and whilst functional, is perceived to be less effective. Solutions to premature disposal were explored through the co-creation of is perceived to be less effective. Solutions to premature disposal were
design concepts and design features were tested via an online survey.

Vacuum cleaner users were clustered into four cleaner types; Spartan, Minimal, Caring and Manic. Overall, respondents reported that improving the ease of maintaining vacuum cleaners would be the most effective way to help them to increase their yacuum cleaner's longevity. Across all cleaner types maintenance levels were low, although Caring and Manic cleaners were significantly more likely to undertake such tasks. Motivations for disposal were simglar across cleaner types and we found no evidence that Caring and Manic cleaners disposed of their machines earhier because they were 'worn out.'

We discovered that Caring and Manic cleaners spend the most on their vacuum cleaners, vacuum more often and are the most likely to replace their machine after the shortest period. Those willing to do 'a lot more' to help the environment were significantly more likely to want to 'keep the floors in my home spotlessly clean' and significantly more likely to indicate that they preferred their vacuum cleaner to look new. lessly clean' and significantly more likely to indicate that they preferred their vacuum cleaner to look new.
Consequently, the paper proposes that design interventions to increase vacuum longevity should be targeted toward Caring and Manic eleaners and concludes with key design recommendations for these two cleaner types.

(C) 2019 .

\section{Introduction}

Every year around two million tonnes of electricat and electronic equipment (EEE) are discarded by householders and companies in the UK (HSE, 2018). Vacuum cleaners have widespread ownership in the UK: $87 \%$ of the population own at least one (AMNTEL, 2010). Sustainable consumption requires increased product longevity (Cooper, 2000), not least because the fast throughput of consumer goods adds to the threat of climate change due to embodied greenhouse gas emissions (Allwood et al. 2012). Longer product lifetimes are also an integral part of the waste reduction agenda (HM

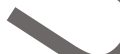

Reference to this paper should be made as follows: Harmer L., Cooper T, Fisher T., Salvia G. and Barr C. 'Design, Dirt and Disposal: Influences on the Maintenance of Vacuum Cleaners'.

* Corresponding author

Email address: 1.a.harmer@1boro.ac.uk (L. Harmer)

https://doi.org/10.1016/j.jclepro.2019.04.101

0959-6526/ @ 2019 .
Government, 2013). The environmental implications of repairing or replacing a vacuum cleaner are linked directly to frequency of use and its energy rating (Pérez-Belis et al., 2017). Research by GallegoSchmid et al. (2016) predicts that the 2013 European Commission ecodesign requirements for vacuum cleaners could reduce their environmental impact by $37-44 \%$. As they postulate, after implementation of the directive, more energy efficient vacuum cleaners and limited availability of some raw materials will strengthen the environmental argument for increasing vacuum lifetimes and managing end-of-life through circular business models (Bakker et al., 2014).

Vacuum cleaners are regularly replaced: over a three year period, $44 \%$ of UK households bought a vacuum cleaner, making it the second most frequently bought domestic appliance (MINTEL, 2013a). They are the second largest source of embodied emissions among electrical products in the UK (Product Sustainability Forum, 2012), and consumers, on average, expect them to last only 5 years (WRAP, 2013a); indeed $28 \%$ of vacuum cleaner purchases in 2012 
were to replace a vacuum cleaner under that age that were reported to have broken down or proved unreliable (WRAP, 2013b).

Understanding the factors that shorten the longevity of vacuum cleaners therefore deserves further investigation. Research by the European Commission's Joint Research Council used life cycle analysis to show that "extending the lifetime of vacuum cleaners generally implies benefits for both environmental and economic perspectives for most scenarios considered" (Bobba et al., 2015: p2).

Vacuum cleaners are mature products, having evolved over the past 100 years. Manufacturers have sought to offer new purchase incentives and development has followed changes in users' lifestyles and aspirations, focusing on innovation in ease of use and saving time, whilst prices in real terms have fallen dramatically (Which?, 2017a,b).

This paper investigates the complex factors affecting the lifespan of vacuum cleaners by reporting on the research undertaken as part of a larger project, Dirt, Damage, Servicing and Repair of Vacuum Cleaners (Cooper et al., 2016). Such 'real world research' (Robson, 2011) works simultaneously with the material factors that shape designs and the cultural matters that make these relevant to people. Both are in play in this paper, so the relationship of users to dirt and vacuum cleaners is contextualised and the findings discussed with reference to the social sciences.

The paper explores four dimensions of the relationship of users to dirt and vacuum cleaners - The Experience of Using and Maintaining a Vacuum Cleaner, The Cleanliness of the Home, The Dirt Inside the Vacuum Cleaner, and The 'Clean Look' of the Vacuum Cleaner - and the implications for the repair and disposal of vacuum cleaners. After setting out the objectives and reviewing these areas, the paper describes the rationale for the research methodology and outlines the characterisation of four types of cleaner (i.e. user), who negotiate cleaning in different ways. Findings from the empirical research are then outlined, structured around the dimensions and the implications for repair and disposal. Design features that could counter the premature disposal of vacuum cleaners are then explored in relation to the characterised cleaner types.

\section{Objectives}

The Dirt, Damage, Servicing and Repair of Vacuum project involved researchers in seeking to learn about vacuum clear design, use, repair, maintenance and disposal. This paper addresse three of the project's objectives; to identify vacuum cleaner us lationship with dirt and their cleaning habits; to assess how this relationship affects product life-spans; and to explore whether design features could increase longevity by improving the users' experiences of removing dirt.

\section{The relationship of users to dirt and vacuum cleaners \\ 3.1. The experience of using and maintaining a vacuum cleaner}

From Hoover's advertisements in the early 1920 s to the more recent $\mathrm{G}$ Tech commercials, the vacuam cleaner has been advertised to appeal to the reluctant cleaner bysuggesting that it creates enjoyable experiences where once there was only cleaning drudgery, offering 'liberation from domestic chores' (Stoppani, 2011: p57).

Ever since their invention, vacuum cleaners have been sold on the ease and effectiveness of removing dirt that they offer, alongside the aesthetics of cleanliness and newness (Harmer et al., 2015). As machines, they have been envisaged as almost 'magic' items for cleaning. Jackson (1992) reports on advertisements promoting the first vacuum cleaners, quoting one from the 1920s, suggesting that they offer "easy, effortless cleaning of every nook and corner" and provide for "leisure and freedom." Jackson concludes "this reveals something of the mythology of the "mechanical servant" it is as if the vacuum cleaner steers itself around the house unaided"/(Jackson, 1992, p. 166). According to Douglas (1966), people want to be pure and seem to enjoy the processes of purification that might make them so. Even so, it is possible to interpret cleaning without the assistance of technological magic as not enjoyable but mere drudgery, akin to service or subjugation.

Schifferstein and Zwartkruis-Pelgrim 2008) assert that creating an enjoyable experience is a principal method of enhancing emotional attachment to a product, and those to which we are most attached are liable to be the ones we keep for longer. They describe product pleasure as rooted in a combination of product meaning, monetary value and utility, and product attachment as the strength of the bond that these factors create, i.e. how willing we are to keep a product. Factors influencing shorter vacuum cleaner lifetimes are clearly complex (Salvia et al., 2015). However, the connection between enjoyable product experience, emotional attachment, product maintenance and longevity suggests that one factor in the relatively short lifetimes of modern vacuum cleaners is that they are either not as enjoyable to use as promised, or that any positive experience (i.e. satisfaction) of usability or removal of dirt does not last.

In this paper we make the distinction of product experiences that are enjoyable as fulfilment during the task (Schifferstein and Zwartkruis-Pelgrim, 2008) and satisfaction as fulfilment after the task (Churchillyr and Surprenant, 1982). Whilst adverts might portray the task of vacuuming with a 'mechanical servant' as enjoyable, it is perhaps understanding satisfaction, as a longer, reflective attribute, that offers greater potential for increasing emotional attachment and thereby promote vacuum cleaner longevity. MINTEL (2010) ranked

thereby promote vacuum cleaner longevity. MINTEL (2010) ranked

cuum and revealed that after suction power (a proxy for effectiven dirt removal), these relate closely to an enjoyable experience: vacuum cleaners should be easy to move around (2nd) and lightweight (3rd)

\section{The cleanliness of the home}

Dirt challenges the body's margins, and its effective removal is a means to avoid disgust (Rozin et al., 1993), as well as satisfying social norms. Whilst vacuuming might be considered a chore, the removal of dirt can be both satisfying and enjoyable because there is pleasure to be had in protecting the self from contamination an thereby creating an appropriate social face. Enjoyment may also come from the physical movement necessary in using a vacuum cleaner and the visible, instant rewards of removing dirt. There is on completion, satisfaction: a home with a visibly clean carpet with its neat brushed pile and (for the social face) suitable for the reception of guests.

In the practice of home cleaning, dirt is a focus for complex, overlapping and sometimes contradictory concerns that are deeply embedded in our culture (Fisher et al., 2015). For example, dirt may be understood both as a danger to health and a mark of social incompetence and low status. The dust that vacuuming seeks to capture has material qualities: it sticks to human skin, gets up noses, covers surfaces of objects and clouds the air - material effects that stimulate a desire to remove it. Theoretical approaches to dirt may emphasise either its material or cultural aspects. The influential position developed by Douglas (1966) suggests that its material properties and health implications are less significant stimuli for its removal than the 
socio-cultural system that marks it out as dangerous. More recent theorists, however, have been concerned to put the 'material' back into Douglas's account of material pollution, emphasising that dirt is in reality both physical and symbolic (Lagerspetz, 2018). Dant and Bowles's (2003) account of the mechanics of dealing with dirt exemplifies this newer approach, emerging from the so-called 'material turn' in the humanities and social sciences (see, for instance, Pierides and Woodman, 2012). On this understanding, vacuuming is pleasurable because it is both (physically) efficacious and (culturally) 'good'.

\subsection{The dirt inside the vacuum cleaner}

Ever since the vacuum's inventor, Hubert Cecil Booth (ICE, 1955) reputedly demonstrated the cleaning principle by placing a handkerchief on a restaurant chair and sucking through it, the power of trapping and disposing of dirt became evident. Vacuums capture the dirt that was once inside the home, to dispose of it outside. Immediately and literally in the case of the Booth's first horse drawn vacuum cleaners, which sat outside on the street. Nevertheless, current machines still 'lock' the dirt inside them, assuring users of the effectiveness of vacuuming.

The importance of the vacuum exhaust air being clean and free from smell and dust confirms the principle of trapping dirt; a vacuum which sucks up dirt only to redistribute the dirt as finer particles undermines the machine's capabilities. The growth of bagless cleaners has also changed the user's relationship of vacuums to dirt. Dirt is no longer permanently contained, the offending material is reassuringly visible and trapped, but must also be released to be disposed of. The bagless vacuum makes it possible for the vacuum user to evidence the work they and the vacuum have done; however, contact with dir is not over, creating new interactions with dirt, and eliciting both attraction and repulsion that are worthy of investigation.

\subsection{The 'clean look' of the vacuum cleaner}

From the perspective of design, Forty (1986) identifies how niture without carving or mouldings using fused, hard materials that do not absorb dirt, were responses to the growing association in th 20th century between dirt and disease. These modernist preferen meant vacuum cleaners could be kept looking clean, intertwining abstract rhetoric of hygiene with the actuality of performance. These were designs that not only looked clean but were clean: "The history of the vacuum cleaner is a good example of the commercial applications of the phobia against dirt, and of the way appearance and styling were affected by the imagery of hygiene" (Forty, 1986: p174).

As well as collecting dirt, vacuum cleaners may themselves appear dirty: they may get marked or damaged in use, or become electrostatically charged, attracting dust to their (plastio) surfaces. This loss of physical 'gloss' with age is, however, only partly responsible for products looking used: styling obsolescence also plays a part (Cooper, 2004). As early as the 1930 s vacuum cleaner manufacturers regularly changed the appearance of their designs to stimulate sales, using progressive, futuristic motifs, following the lead of the automobile industry (Forty, 1986). Henry Dreyfuss's design for the 1950s Hoover Constellation perhaps exemplifies this approach, its looks inspired by the possibility of space. its movement influenced by the potential of futuristic travel using an ar cushion to help levitate it. 'Newness' drives sales and the constant arrival of new models means that as a vacuum cleaner begins to look dirty it simultaneously looks dated, losing both its physical 'gloss' and its aesthetic appeal.

\section{Vacuum cleaner repair and disposal}

By simple logic, motivations for disposing of a vacuum cleaner are linked with motivations for purchase. Just as the potential for enjoyment (or satisfaction, at least) might motivate purchase acuum cleaner that becomes less enjoyable to use is liable to be replaced. A survey by MINTEL (2010) found that $80 \%$ of people would only buy a new vacuum cleaner if their old one was broken. What constitutes being 'broken', however, is perceived in different ways (Salvia et al., 2015). Thus new machines may replace ones that would be cost effective to repair (Which?, 2014a) or are not working properly because poor maintenance has led to worn components or blocked filters.

These functional drivers for disposing of vacurum cleaners are reinforced by changes that have dramatically reduced manufacturing costs. The cost of the first vacuum cleaners imported to Britain in 1912, £25, was equivalent to a housemaid's annual wage (Jackson, 1992). According to Statista (2018) oyer two thirds of vacuum cleaners purchased in 2017 were under $£ 200$, a considerably lower cost in real terms. Such reduced cost increases the likelihood of psychological obsolescence (Cooper, 2004). Cooper and Mayers (2000) identified that the low cost of replacement, combined with concern that products may become out of date', leads some consumers to feel that they have had value from a product after a relatively short period. According to Which? (2014b), vacuum cleaners are still typically financially viable to repair up to when they are seven years old. However, extending the lifetime of 'workhorse' products such as vacuum cleaners, is complex: "the value of repairing such products was often seen as highly questionable. Perceived inconvenience, perceived expense (of both labour and parts) and the relatively low prices of replacement products all contributed to participants' unwillingness to get workhorse products repaired" (Brook Lyndhurst,

11: p6). Repair may also create additional concerns for the owner,

will consider efficiency in picking up dirt against a new counterpart and whether money spent repairing a used 'dirty' machine would be better spent on a new machine with potentially increased performance.

The result is a potential gap between actual and environmentally desirable product lifetimes, whether understood as intended, ideal or predicted (Gnanapragasam et al., 2018). With high levels of ownership and a market nearing saturation, vacuum cleaner manufacturers are challenged to create new ways of triggering replacement purchases. Nonetheless, chasing further cost reductions or improving user experiences may not be the only strategy for manufacturers. MINTEL concluded that for low cost household cleaning products "brands need to encourage consumers to shift some of their focus away from 'lowest price' to looking for better value in terms of longer-lasting products" (MINTEL, 2013b).

The disposition of owners towards 'newness' may intersect with their feelings about dirt in determining the point at which a vacuum cleaner is discarded. Campbell (1992) identifies three types of consumer motivation for buying new products: a desire to acquire a new possession; for the pristine; and for the technically improved or novel. These consumer types may each help to explain why people replace vacuum cleaners and their choice of new machine.

\section{Research methodology}

The research presented in this paper was undertaken through a project funded by Defra's Action Based Research Programme (reference no. EV0554) and in collaboration with a major vacuum 
cleaner manufacturer. The methodology drew upon action research and adopted the Double Diamond process developed by the Design Council (2006). The interviews, focus groups and co-creation research, summarised below, were conducted in Nottingham and the surveys conducted nationally.

\subsection{Action Based research}

Defra's Action Based research programme sought to engage industry and research institutions in participatory and practical ways to find solutions to influence consumer behaviour toward more sustainable practices. The timescales of the project meant that it was not possible to adopt fully an action research approach (Kemmis et al., 2013) however it did inform a methodology driven by an extensive ethnographic investigation of user practices. Through which motivations for premature vacuum cleaner disposal were explored by working primarily with users but also with insights from a vacuum cleaner repairer and the collaborating manufacturer.

Through the initial project stages, it became apparent that the relatively short life of many vacuum cleaners could be treated as a design problem and addressed within a design process. However, the feedback and iterative loops of an action research approach were used and, whilst it was not possible to measure changes in behaviour through the testing of prototypes, underlying user motivations to behaviour change were sought through both theoretical and practical means. Denscombe (2014) notes that action research can be used to create guidelines for effective practices, and a toolkit aimed at manufacturers was therefore produced as a project output.

\subsection{Double Diamond design process}

The Double Diamond Design Process was selected as a clear, graphical way to structure the project research methods to consider the design of the vacuum cleaner in relation to purchase and disposa motivations. In line with the Design Council's recommendations, th 'Discover' phase sought to identify user needs through market user research. The 'Define' phase interpreted these user needs int business objectives to clarify the problem: i.e. the current market requires a large turnover of product in order to be profite resulting in increased environmental impacts. The 'Develop' phas co-created design features and investigated purchasing models, and the 'Deliver' phase created refined concepts and the toolk

\subsection{Research methods}

The research utilised mixed methods for collecting primary data, including interviews, focus groups, workshops and two national surveys. A variety of vacuum cleaner design features were generated by engaging manufacturers, users and design students in seeking commercially attractive solutions to the problems identified. The research sought to collect qualitative insights about purchase, use and disposal that could be developed into features to be tested using a quantitative survey. The methods and their application in the project are summarised below (Table 1)

The mapping of these methods onto the Double Diamond process is shown in Fig. 1. The Discover stage involved three methods (A-C) to investigate and understand the relationship of users to cleaning, dirt and their vacuum cleaners. The Define stage used an online survey (D) to explore whether insights revealed by households in the Discover phase (relating to vacuum cleaner longevity) were representative of the UK population.
Table 1

Research Methods discussed in this paper and used in the 'Dirt, Damage, Servicing and Repair of Vacuum Cleaners' project (Cooper et al, 2016).

\begin{tabular}{|c|c|c|}
\hline Research Method & Detail & \\
\hline $\begin{array}{l}\text { A. On-street user } \\
\text { interviews }(\mathrm{n}=114)\end{array}$ & $\begin{array}{l}\text { Face-to-face street } \\
\text { questionnaire conducted in } \\
\text { Nottinghamshire with owners } \\
\text { of vacuum cleaners } \\
\text { responsible for maintenance } \\
\text { and upkeep of their vacuum, } \\
\text { covering vacuum ownership } \\
\text { and cleaning practices. }\end{array}$ & $\begin{array}{l}\text { f consum } \\
\text { ating to } \\
\text { gand } \\
\text { angevity. }\end{array}$ \\
\hline $\begin{array}{l}\text { B. In-depth user } \\
\text { interviews }(n=7) \\
\text { and interviews with } \\
\text { a vacuum cleaner } \\
\text { repairer and a } \\
\text { manufacturer }\end{array}$ & $\begin{array}{l}\text { Users selected from on-street } \\
\text { interviewees were } \\
\text { interviewed in their homes } \\
\text { about cleaning practices. } \\
\text { Local repairer and } \\
\text { manufacturer inter jewed at } \\
\text { their premises. }\end{array}$ & $\begin{array}{l}\text { dentification of } \\
\text { consumer issues } \\
\text { relating to } \\
\text { vacuuming, product } \\
\text { longevity and } \\
\text { disposal. }\end{array}$ \\
\hline $\begin{array}{l}\text { C. Vacuum cleaner } \\
\text { teardowns }(\mathrm{n}=12)\end{array}$ & $\begin{array}{l}\text { 'Discarded' vacuum cleaners } \\
\text { obtained from a range of } \\
\text { sources, inclyding } \\
\text { interviewees, recycling } \\
\text { centres and trade-ins. } \\
\text { Complete teardown and }\end{array}$ & $\begin{array}{l}\text { Identification of } \\
\text { technical issues } \\
\text { relating to product } \\
\text { longevity and vacuum } \\
\text { disposal. }\end{array}$ \\
\hline & $\begin{array}{l}\text { Conducted at Nottingham } \\
\text { Trent University. Participants } \\
\text { recruited across cleaning } \\
\text { types. }\end{array}$ & $\begin{array}{l}\text { Investigation of } \\
\text { findings from stages } \\
\text { A-C to see if they are } \\
\text { reflected in a larger } \\
\text { sample. } \\
\text { Generation of design } \\
\text { concepts to increase } \\
\text { vacuum cleaner } \\
\text { longevity with } \\
\text { consumers. }\end{array}$ \\
\hline & $\begin{array}{l}\text { Conducted at Nottingham } \\
\text { Trent University. Participants } \\
\text { recruited across cleaning } \\
\text { types. }\end{array}$ & $\begin{array}{l}\text { Review and } \\
\text { development of } \\
\text { concepts for vacuum } \\
\text { cleaner longevity } \\
\text { with consumers. }\end{array}$ \\
\hline $\begin{array}{l}\text { Second survey } \\
(\mathrm{n}=552)-\text { see } \\
\text { Appendix } 5\end{array}$ & $\begin{array}{l}\text { Survey of UK households } \\
\text { conducted using an on-line } \\
\text { panel. }\end{array}$ & $\begin{array}{l}\text { Review of concepts } \\
\text { with large sample of } \\
\text { consumers to } \\
\text { understand if design } \\
\text { features are } \\
\text { appropriate. }\end{array}$ \\
\hline $\begin{array}{l}\text { H. Stakeholder } \\
\text { interviews (5 } \\
\text { vacuum cleaner } \\
\text { manufacturers and } \\
\text { one repairer) - see } \\
\text { Appendix } 6\end{array}$ & $\begin{array}{l}\text { Stakeholders sent outputs and } \\
\text { proposals from second survey } \\
\text { prior to semi-structured } \\
\text { telephone interviews. }\end{array}$ & $\begin{array}{l}\text { Discussion of } \\
\text { consumers' response } \\
\text { to concepts and } \\
\text { design features with } \\
\text { stakeholders to } \\
\text { understand } \\
\text { commercial } \\
\text { strategies for } \\
\text { longevity. }\end{array}$ \\
\hline
\end{tabular}

The Develop phase drew upon findings from the online survey (D) on attitudes and behaviour towards cleaning and dirt. In addition, using insights from users and manufacturers (B), design features were created through iterative 'co-creation' methods (E, F). Whether the proposed design features resonated in a larger population was explored through a second online survey $(\mathrm{G})$, and consumers' responses were then discussed in interviews with industry stakeholders $(\mathrm{H})$. Th output of the Deliver phase - the 'solution' of the project - was delivered in the form of a toolkit.

\subsection{Clustering types of cleaners}

Vacuuming experiences need to be contextualised within wider cleaning practices. Enjoyment of cleaning tasks and the satisfaction 


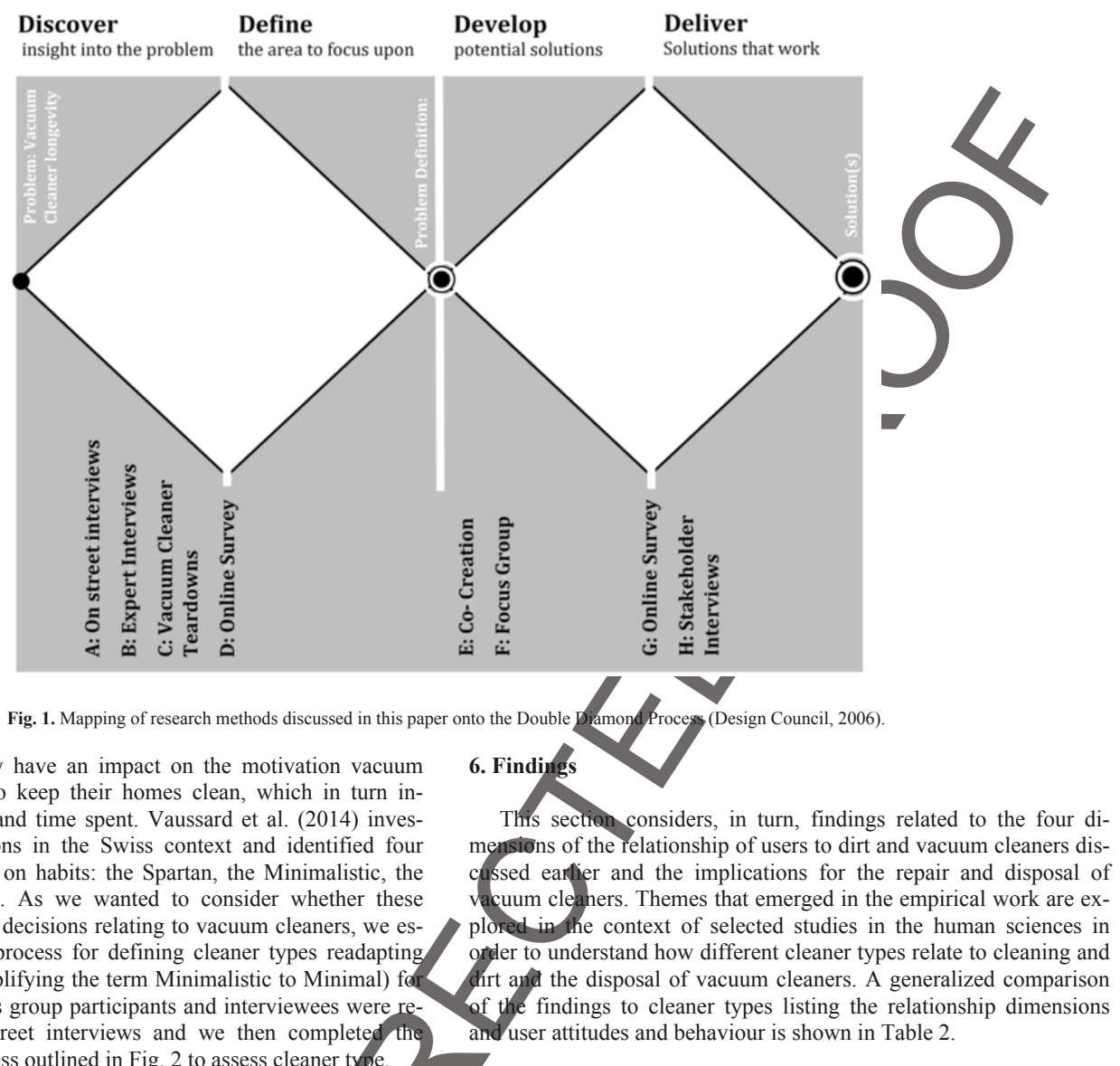

gained from them may have an impact on the motivation vacuum cleaner owners have to keep their homes clean, which in turn influences efforts made and time spent. Vaussard et al. (2014) investigated these motivations in the Swiss context and identified four types of cleaner based on habits: the Spartan, the Minimalistic, the Caring and the Manic. As we wanted to consider whether these cleaner types influence decisions relating to vacuum cleaners, we established a clustering process for defining cleaner types readaptin Vaussard's model (simplifying the term Minimalistic to Minimal) our survey work. Focus group participants and interviewees were recruited from the on-street interviews and we then completed
cleaner clustering process outlined in Fig. 2 to assess cleaner type.

Only owners of vacuums were permitted to answer the surveys. the first online survey questions covered demographics, attitudes wards the environment and a range of questions about their yacumm cleaner and cleaning practices and the importance of cleanliness. This made it possible to assign almost all respondents $(96 \%)$ to one of the four groups, spread as follows: Spartan cleaners (12\%). Mirima cleaners $(34 \%)$, Caring cleaners $(40 \%)$ and Manic cleaners $(10 \%)$. These cleaner types were identified and used in subsequent stages of the project.

6.1. The experience of using and maintaining a vacuum cleaner

Enjoyment and satisfaction gained from vacuum cleaning was explored in several phases of the research. During the on-street interviews all types of cleaners reported that they gained satisfaction from vacuuming. However, the first online survey revealed that many people do not regard cleaning the home as an enjoyable (or even engaging) task, with nearly $40 \%$ of respondents wishing that someone else would clean their home.

The co-creation workshop explored vacuum cleaner users' cleaning experiences, particularly in relation to prolonging a machine's lifetime. Participants were invited, in teams, to draw upon their own experience to describe their most enjoyable and most frustrating vacuum cleaners. Similarities existed across all teams. Participants indicated that they considered vacuum cleaning most enjoyable when using a machine that is easily manoeuvred (e.g. lightweight and cordless), user-friendly (e.g. easy to take apart), adaptable (including accessories), powerful (e.g. high suction performance), appealing (e.g. smooth aesthetic and sensible price) and which requires low maintenance (e.g. easy to empty and repair). By contrast, vacuum cleaning was most frustrating when the machine was difficult to manoeuvre (e.g. heavy, wobbly or unstable), not user-friendly (e.g. survey respondents were asked about vacuum ownership and thei environmental opinions. Cleaner types were then compared, with reference to frequency of vacuum replacement and whether they would like to do more to help the environment. 


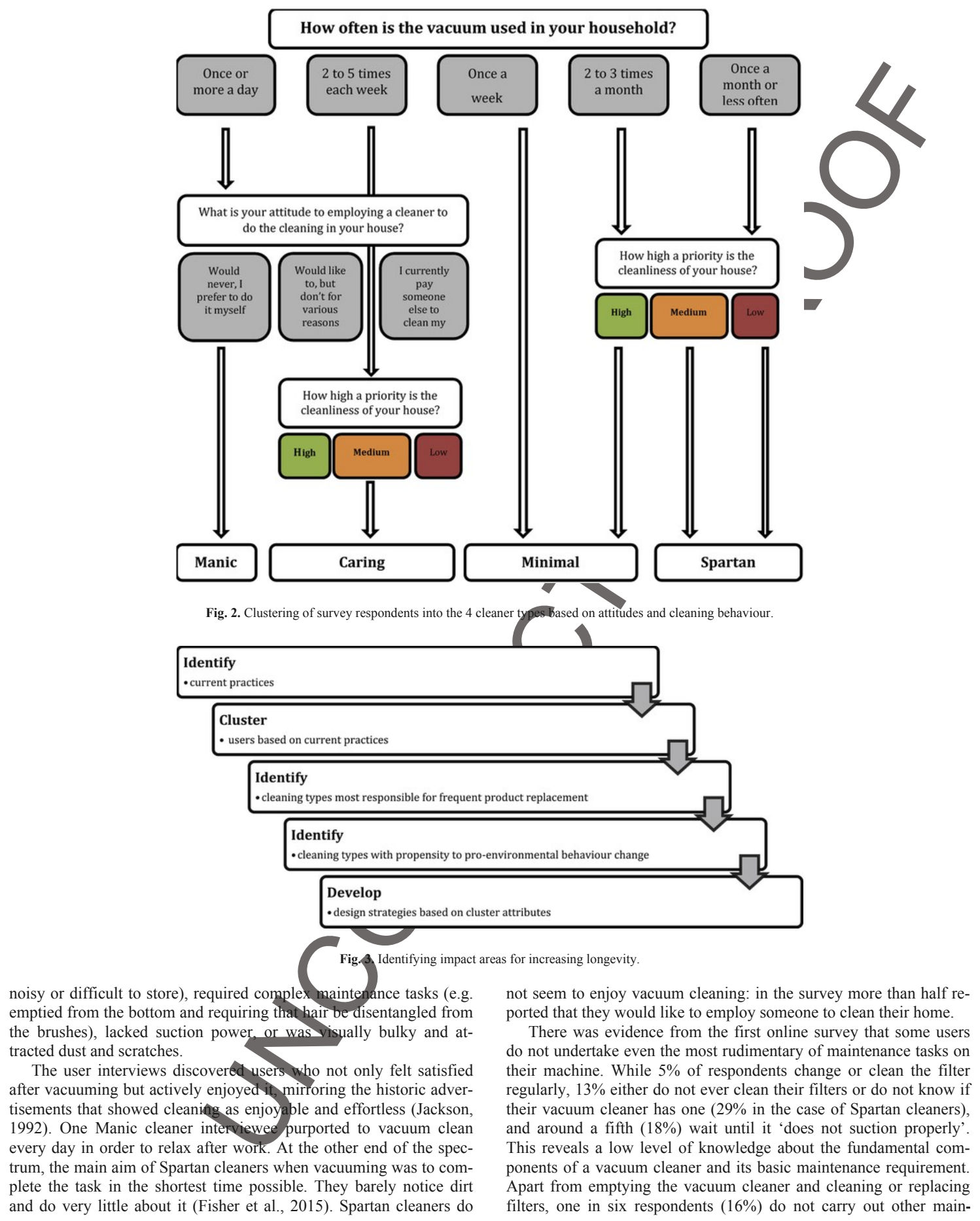


Table 2

Generalized comparison of cleaner types with relationship dimensions and user attitudes and behaviour from the first online survey (D) and second online survey (G)

\begin{tabular}{|c|c|c|c|c|c|c|}
\hline \multirow[t]{2}{*}{$\begin{array}{l}\text { Cleaner } \\
\text { Type }\end{array}$} & \multicolumn{4}{|c|}{ Relationship dimensions $(D)$} & \multicolumn{2}{|c|}{ User attitudes and behaviour } \\
\hline & $\begin{array}{l}\text { The Experience of } \\
\text { Using and Maintaining } \\
\text { a Vacuum Cleaner }\end{array}$ & $\begin{array}{l}\text { The Cleanliness of the } \\
\text { Home }\end{array}$ & $\begin{array}{l}\text { The Dirt Inside } \\
\text { the Vacuum } \\
\text { Cleaner }\end{array}$ & $\begin{array}{l}\text { The 'Clean Look' } \\
\text { of the Vacuum } \\
\text { Cleaner }\end{array}$ & Maintenance $(D)$ & $\mathrm{D}$ \\
\hline Spartan & Dislikes cleaning & $\begin{array}{l}\text { Low to medium } \\
\text { priority - vacuums } \\
\text { once a month or less }\end{array}$ & $\begin{array}{l}\text { Doesn't mind } \\
\text { contact with } \\
\text { dirt }\end{array}$ & $\begin{array}{l}\text { Unconcerned about } \\
\text { wear }\end{array}$ & $\begin{array}{l}\text { Unconcerned about } \\
\text { efficiency, very low } \\
\text { maintenance }\end{array}$ & $\begin{array}{l}\text { Lower } \\
\text { envivonmental } \\
\text { eoneern }\end{array}$ \\
\hline Minimal & $\begin{array}{l}\text { Cleaning seen as a } \\
\text { necessity }\end{array}$ & $\begin{array}{l}\text { Medium priority - } \\
\text { vacuums two to three } \\
\text { times a month }\end{array}$ & $\begin{array}{l}\text { Accepts contact } \\
\text { with dirt }\end{array}$ & $\begin{array}{l}\text { Doesn't mind some } \\
\text { wear }\end{array}$ & $\begin{array}{l}\text { Some concern about } \\
\text { efficiency, low } \\
\text { maintenance }\end{array}$ & $\begin{array}{l}\text { Low } \\
\text { environmental } \\
\text { concern }\end{array}$ \\
\hline Caring & $\begin{array}{l}\text { Cleaning seen as a } \\
\text { necessity, some } \\
\text { enjoyment }\end{array}$ & $\begin{array}{l}\text { Medium to high } \\
\text { priority - vacuums two } \\
\text { to five times a week }\end{array}$ & $\begin{array}{l}\text { Tolerates } \\
\text { contact with } \\
\text { dirt }\end{array}$ & $\begin{array}{l}\text { Likes vacuum to } \\
\text { look new }\end{array}$ & $\begin{array}{l}\text { Concerned about } \\
\text { efficiency, more } \\
\text { maintenance }\end{array}$ & $\begin{array}{l}\text { High } \\
\text { environmental } \\
\text { concern }\end{array}$ \\
\hline Manic & Enjoys cleaning & $\begin{array}{l}\text { High priority - } \\
\text { vacuums more than } \\
\text { five times a week }\end{array}$ & $\begin{array}{l}\text { Avoids contact } \\
\text { with dirt }\end{array}$ & $\begin{array}{l}\text { Requires vacuum to } \\
\text { look new }\end{array}$ & $\begin{array}{l}\text { Concerned about } \\
\text { efficiency, higher } \\
\text { maintenance }\end{array}$ & $\begin{array}{l}\text { Higher } \\
\text { environmental } \\
\text { concern }\end{array}$ \\
\hline
\end{tabular}
icantly higher in the case of Spartan cleaners than Caring or Manic cleaners $(31 \%$ cf. $10 \%$ and $8 \%$, respectively, $\mathrm{p}<0.05)$.

\subsection{The cleanliness of the home}

The first online survey findings helped to explain people's attitudes and behaviour towards cleaning their homes, thereby indicating their reaction to the presence of dirt in the home. It revealed that $64 \%$ of respondents were the main user of the vacuum cleaner while just under a quarter $(23 \%)$ shared this responsibility. In other cases, a partner or spouse $(10 \%)$ or another adult $(2 \%)$ was the main user. Around three-quarters of respondents either use their vacuum cleaner 2 to 5 times a week $(41 \%)$ or once a week $(33 \%)$. At the extremes, $13 \%$ vacuum once or more a day, while $4 \%$ vacuum only once a month or less often. The other $10 \%$ vacuum 2 or 3 times a month.

Cleanliness in the home is a 'high priority' for nearly a third of re spondents $(31 \%)$, while the majority $(59 \%)$ rate it as a 'medium pri ority' and $10 \%$ a 'low priority'. This aligns with research by MINTEL (2013a), which concluded that nearly three quarters of adults in the UK 'really care' about their home being clean, laking pride in maintaining a clean home. The priority put on home cleanliness relates to frequency of vacuum cleaning and, to some extent, attitudes to the environment; respondents willing to do 'a lot more' to help the environment were significantly more likely to strongly agree that 'it is really important to me that I keep the floors in my home spotlessly clean to ensure the well-being of my family/household' than those willing to do 'a bit more', or 'happy with what I do' $(39 \%$ cf. $15 \%$ and $17 \%$ respectively, $\mathrm{p}<0.01$ )

Over two thirds of respondents agreed (46\%) or strongly agreed $(21 \%)$ that keeping floors 'spotlessly clean in their home is important to ensure the wellbeing of their family/household, consistent with findings from MINTEL (2013) Only $8 \%$ either disagreed or disagreed strongly. Cleaning the home is usually an activity carried out by household members; onlya very small proportion of respondents (4\%) currently pay someone else to help clean their home. Although $60 \%$ would never consider employing a cleaner, around a third $(35 \%)$ do not employ a cleaner but would like to, suggesting that they regard cleaning as unenjoyable.

All cleaner types vacuum the same kind of physical dirt, but they vary in how sensitive they are to it. Attempts to limit contact with dirt are greater with Manic cleaners, as demonstrated in responses from the first online survey (Fig. 4). User interviewees reported having dust allergies, suggesting a greater concern about the wafting dirt that the vacuum eleaner is designed to control. When emptying bags or canisters, this undifferentiated matter will fly around and may enter their noses and make them sneeze. The visibility of dirt (especially with bagless cleaners) was considered both positive and negative. For some, it increased the enjoyment of vacuuming and they reported a nse of satisfaction and achievement at being able to see dirt col-

cted. Several of our interviewees reported how they took care to avoid contact with dirt when emptying their vacuum cleaners.

The user interviews suggested that the sense of disgust engendered by the dirt that vacuum cleaners capture may have a role in their disposal. One interviewee, a Caring cleaner, commented on ping their vacuum cleaner free from dirt: "It's the thought I suppose of all that dirt just sitting there, and if there was a piece of food that accidently got sucked up, rotting away inside there ... urghh ... getting stinky." A machine that is simultaneously dirty on the outside and reveals dirt captured on the inside may need only relatively minor mechanical problems or external damage to prompt replacement. Indeed, one vacuum cleaner manufacturer suggested that "the growth of bagless products ... has promoted the perception of products being unclean and the early disposal of products as a consequence."

\subsection{The 'clean look' of the vacuum cleaner}

The first online survey investigated users' responses to the loss of their vacuum cleaners' physical 'gloss' with use or age. Only $10 \%$ of respondents reported dissatisfaction when their machine gets marked or chipped. Nearly half $(47 \%)$ prefer it to look new but 'tolerate' visible signs of wear, while $43 \%$ 'do not care' if it shows signs of wear; vacuum cleaners are generally not displayed but kept out of sight in a cupboard $(62 \%)$ or hidden from view in other ways, such as behind a door or sofa $(17 \%)$. Manic $(60 \%)$ and Caring $(59 \%)$ cleaners were significantly more likely to indicate that they preferred their vacuum cleaner to look new but tolerate visible signs of wear than Spartan $(34 \%)$ and Minimal cleaners $(34 \%)(\mathrm{p}<0.05)$. A scratched or dirty 


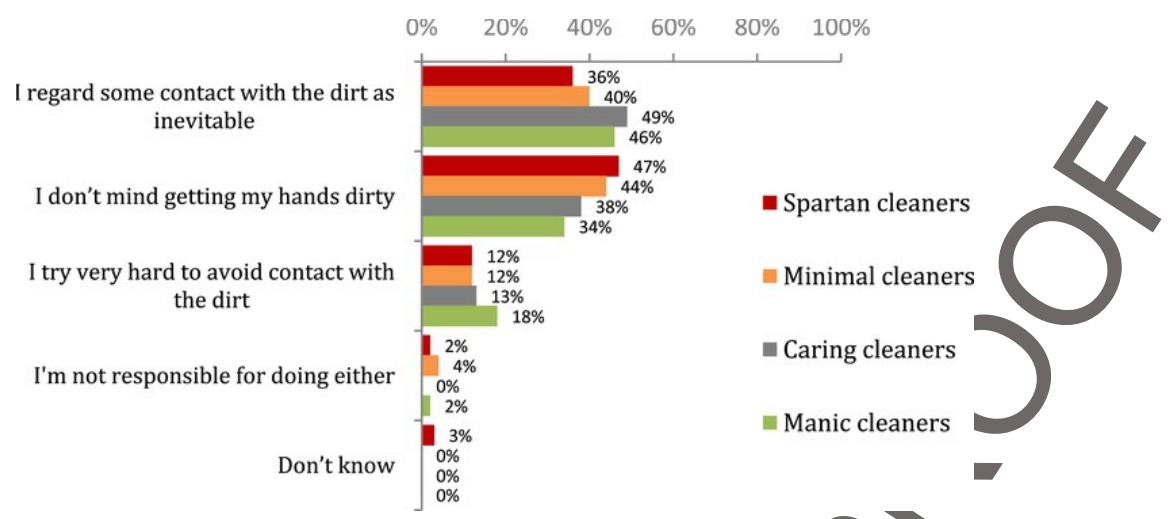
Fig. 4. Response to question "How do you feel about contact with the dirt when either changing the bag/emptying the container or when cleaning the head of your vacuum?" Base
Spartan cleaners (59), Minimal cleaners (174), Caring cleaners (205), Manic cleaners (50).

casing could lead to disaffection, particularly amongst Caring and Manic cleaners, even to the extent of encouraging disposal of vacuum cleaners that are still functional; disaffection is particularly likely for products with connotations of hygiene (Fisher and Shipton, 2009; Fisher, 2004). Around one in six respondents (16\%) replaced their vacuum cleaner because they 'wanted a new one' despite their existing one still working, suggesting that a vacuum cleaner might be perceived as a disposable object that does not warrant time, money or effort.

Some cleaners in the user interviews noticed their machine was looking 'used'; one of them expressed a desire for something 'new and shiny'. Several of those who had more than one vacuum cleaner kept the less favoured one out of sight, in a cupboard or shed, suggesting that as the look of a machine deteriorates with use it may be hidden away, and that dirt may have a role in disposal decisions.

The teardowns illustrated how the plastic materials used modern vacuum cleaners show 'wear' in characteristic ways, wi implications for longevity. Plastics are relatively soft, allowing surface of a vacuum cleaner to acquire scratches and grazes; plastics that start life shiny and transparent become dull and opaque. The electrostatic properties of plastics mean that the very fine dust that vacuum cleaners collect is attracted to the surfaces of casings, which are often made in complex shapes that are not easy to clean.

The 'hygienic design' rhetoric of the machines that Forty (1986) identified remains significant and may have consequences for their longevity, overlapping with current aesthetic aspects in vacuum cleaner designs. Convoluted moulded plastic details characterise the design language used to signify technical advancement, drawing from science fiction, but harbour dirt, and the fragility of mouldings observed in the teardowns invites rapid physical deterioration. On inspection, used vacuum cleaners were often covered with a fine dust through static attraction, and the materials and design features meant that the visual degradation could only be rectified by replacing major plastic components. This aesthetic ageing, the physical contamination involved in vacuuming and the moral frame described earlier could be classed as different components of dirtying': as Forty put it, "pollution is a matter of aesthetics, hygiene or etiquette" (1986: p73).

Dirt, visual damage and ageing aesthetics are all factors implicated in premature disposal (Fisher et al., 2015). It therefore follows that one way to increase longevity would be to use more robus materials and more timeless visual design. Whilst participants in a focus group convened to develop and refine such strategies they were somewhat indifferent to the concept of 'timeless design' of vacuum cleaners, but were positive towards increased attachment and achieving product longevity by tackling users' lack of enjoyment in vacuum cleaning.

Campbell's (1992) neophile' purchase motivation is reflected in the $16 \%$ of al cleaner type respondents who replaced their last vacuum cleaner because they 'wanted a new one'. Around one in seven $(14 \%)$ survey respondents had given their previous vacuum cleaners away and an identical percentage still had them at home, confirming that many machines which are replaced are still operational, while some are kept because owners have some attachment or secondary purpose for them.

The fact that $28 \%$ of survey respondents replaced their last actum cleaner for reasons other than it not working at all or not working efficiently suggests that many items are disposed of because f emotional detachment, and not necessarily when they are no onger capable of undertaking their task. This was also apparent in e discarded but functioning machines observed in the product teardowns: only four of the twelve would not switch on or had no suction. Vacuum cleaners can be subject to psychological obsolescence. An interview with a manufacturer suggested that although guarantees act as important sales drivers by creating product confidence, they are not necessarily utilised by consumers in the event of product failure: "Most of our products have 2 year warranties ... some of our premium products have 6 years, but again I don't think many people use the 6 years ... because designs change, fashions change."

\subsection{Vacuum cleaner repair and disposal}

Most respondents would consider repairing their vacuum cleane or getting it repaired if it developed a fault. Only a small proportion consider repair not to be worthwhile. Vacuum cleaners are not considered worth repairing by $14 \%$ of respondents if they lose suction and $11 \%$ if they do not switch on. In the event of loss of suction owners would consider undertaking the repair themselves if the fault was minor $(27 \%)$ and would definitely do so if they had the necessary information and parts $(26 \%)$; nearly a quarter $(23 \%)$ would conside getting the vacuum cleaner repaired by someone else. Similar proportions were recorded in the event of machines not switching on. Even so, only $18 \%$ have had their current vacuum cleaner repaired, which suggests that the repair option is rarely taken. The gap between the stated attitude and performed action could be due to barriers pre- 
venting execution of the repair option in the case of failure or loss of efficiency, such as the product's design, levels of service, inconvenience and cost (Brook Lyndhurst, 2011).

The first online survey revealed that the most common reason for owners ceasing to use their previous vacuum cleaner was that it had stopped working efficiently $(44 \%)$; overall, nearly two thirds of vacuum cleaners $(66 \%)$ were still functioning in some manner when discarded, as distinct from not working at all. Cleaning or replacing filters is regarded by manufacturers and repairers as essential for keeping vacuum cleaners in good working order, as indicated in instruction manuals. The proportion of survey respondents who replaced their vacuum cleaner due to reduced efficiency was relatively low for Spartan cleaners (33\%), perhaps because they are less concerned about the risk of not having a machine that performs efficiently.

\subsection{Design and assessment of product features}

The duration of the project meant that it was not possible to tria physical design interventions. However, the second online survey was used to assess a range of potential features for increasing vacuum cleaners' longevity which had been generated with users in the cocreation session and reviewed by the focus group. Using the same criteria as in the first online survey (Fig. 2), respondents were again clustered into the cleaner type groups, with a comparable outcome (Spartan cleaners $9 \%$, Minimal cleaners $26 \%$, Caring cleaners $53 \%$ and Manic cleaners 10\%). No significant relationship was found between gender or age and cleaner types.

Most respondents in the second survey had kept their previous vacuum cleaner for no more than 6 years. Around a third (31\%) had kept it for 4-6 years, a similar proportion $(32 \%)$ for $1-3$ years, and small proportion $(6 \%)$ for up to a year. By contrast, nearly one in five $(19 \%)$ had kept their previous vacuum cleaner for 7 or more years One in eight $(12 \%)$ could not remember how long they had kept their previous vacuum cleaner or had not owned one. Spartan cleaners (24\%) were significantly more likely keep their vacuum for over 12 years than other cleaner types (Minimal $4 \%$, Caring $4 \%$, Manic $2 \%$ $\mathrm{p}<0.05)$. This confirms evidence from the first survey that those wh regard cleanliness in the home as less important (i.e. Spartan anc Minimal cleaners) tend to keep their vacuum cleaner for long Caring and Manic cleaners, who vacuum more often than Spartan Minimal cleaners replace their machines more frequently. The proportion who only keep their vacuum cleaner for 1-3 years is significantly higher for Manic and Caring cleaners $(45 \%$ and $34 \%$, respectively) than Spartan and Minimal cleaners $(12 \%$ and $29 \%$ respectively). More than a quarter of Caring cleaners (26\%) had spent $£ 200$ -299 on their current cleaner, a significantly higher proportion than for Minimal cleaners $(15 \%)(p<0.05)$, whereas a mere $4 \%$ spent less than $£ 50$, a significantly lower proportion than for Minimal cleaners $(15 \%)(\mathrm{p}<0.01)$.

The product features were grouped together into four concepts for ease of questioning (Table 3). The features contained within the concepts present different ways to increase longevity that cover the four relationship dimensions: The Expentence of Using and Maintaining a Vacuum Cleaner, The Cleanliness of the Home, The Dirt Inside the Vacuum Cleaner, and The 'Clean Look' of the Vacuum Cleaner. Respondents were asked about each feature in turn, a key aim being to evaluate whether the features would encourage them to keep their vacuum cleaner for longer. Some features directly attempted to improve enjoyment in use and the relationship with dirt (such as dirt parceling), others attempted to resolve the disconnect between perceived function and actual performance (such as an information
Table 3

cepts and their features after development through the co-creation session and focus group.

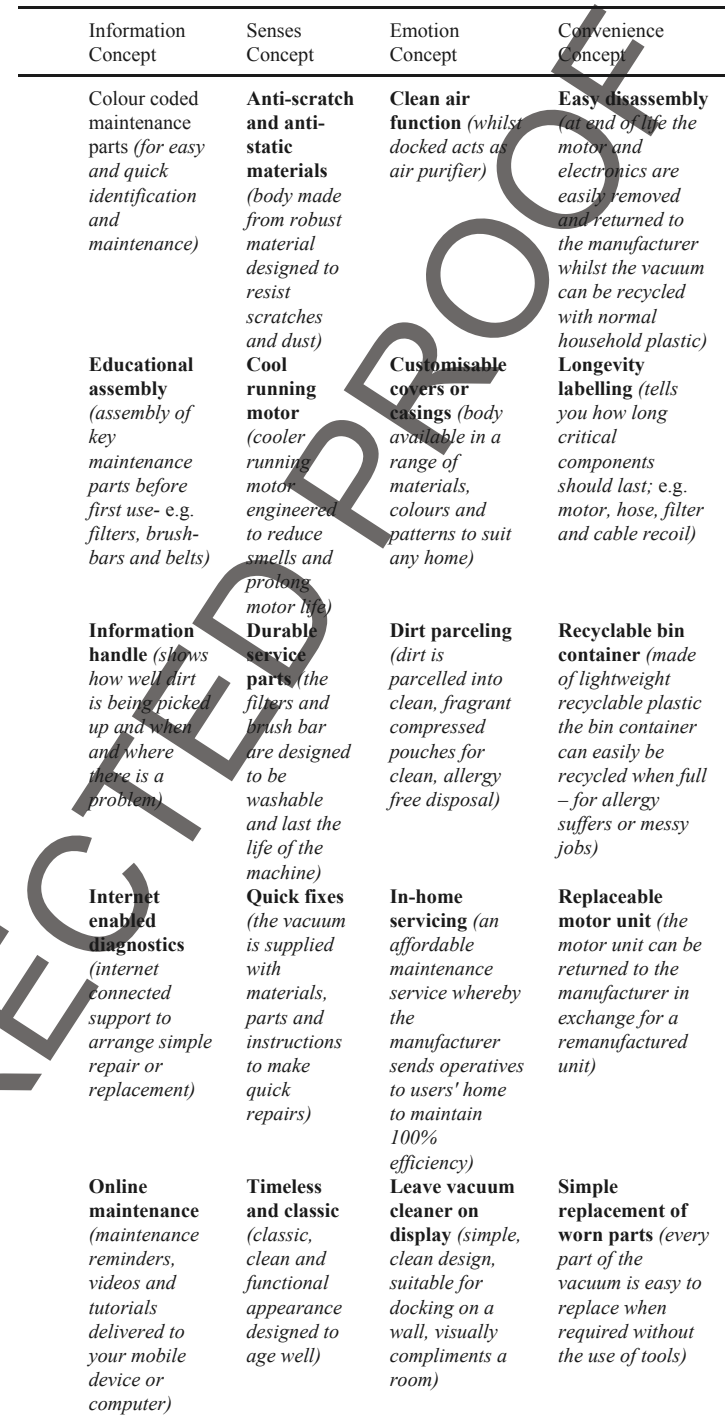

handle). Respondents were asked about the extent to which they agreed whether a feature 'might make me want to keep this vacuum cleaner for longer.' The level of the agreement for each feature was averaged, by mean, on a scale from 1 (strongly disagree) to 5 (strongly agree) (Fig. 5)

For every feature, across all concepts, Caring and Manic cleaners indicated stronger agreement than Spartan and Minimal cleaners that it would help them keep their vacuum cleaner for longer. The design concepts and features are therefore discussed below with a focus on the Caring and Manic cleaner types. 
DManic cleaners $\mathbf{D}$ Caring cleaners Minimal cleaners $\mathbf{D S p a r t a n}$ cleaners

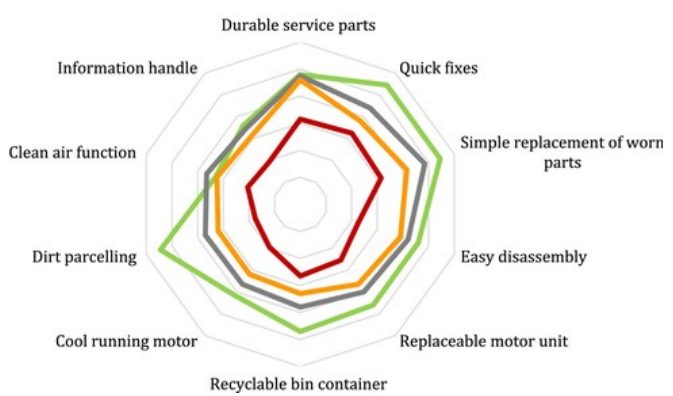

Fig. 5. Ranking of the ten preferred design features that 'might make me want to keep this vacuum cleaner for longer', by cleaner type. The grid lines represent scores for the design features, rising from 3.0 (inner line) to 4.0 (outer line) in 0.2 increments.

\subsection{Information concept}

Within the Information concept, the Information handle (3.64) scored highest as liable to make respondents want to keep a vacuum cleaner for longer. It was also the feature ranked highest for overall appeal, being chosen by $40 \%$ of respondents. Females in particular found it attractive; they were significantly more likely than males to choose it $(45 \%$ cf. $36 \%, \mathrm{p}<0.05)$. It scored highest for Caring and Manic cleaners (3.69 and 3.72 respectively).

\subsection{Senses concept}

Within the Senses concept, Durable service parts was the feature that scored highest as liable to make respondents want to keep a vacuum cleaner for longer (3.90), followed by Quick fixes (3.83). Durable service parts was the feature ranked highest for overall appeal ( $41 \%$ of respondents). Quick fixes had a relatively high scor from Manic (4.09) and Caring (3.88) cleaners. In the case of a Coo running motor (3.68), Manic cleaners scored higher (3.83) Spartan cleaners (3.39), perhaps due to an association of odour with reduced cleanliness. Unexpectedly, Timeless and classic desi (3.35) was the feature that scored lowest for longevity, perhaps due concern that such a product might not fit with respondents changing home décor.

\subsection{Emotion concept}

Dirt parceling (3.68) was the feature in the Emotion concept that respondents scored highest as liable to make them want to keep a vacuum cleaner for longer, with Manic cleaners scoring considerably higher (4.09) than Spartan cleaners (3.35). This suggests that the feature would suit people who vacuum more often and put a higher priority on cleanliness. The feature that scored second for longevity was Clean air function (3.65). Females (3.63) agreed more than males (3.48) that certain features - Clean air function, Dirt parceling and In-home servicing - would encourage them to keep the machine for longer.

\subsection{Convenience concept}

Simple replacement of worn parts was the feature in the Convenience concept that scored highest as liable to make respondents want to keep a vacuum cleaner for longer (3.89). It was also the feature ranked highest for overall appeal especially amongst Manic cleaners (4.09).

Aggregating the results for Caring and Manic cleaners, the five features from among all the concepts that scored highest as liable to make owners want to keep their vacuum cleaner for longer were, in ascending order; Easy Disassembly, Dirt Parceling. Durable Parts, Quick Fixes and Simple Replacement of Worn Parts. Whilst all the relationship dimensions have a bearing on the concepts selected, four relate closely to the dimension 'Experience of Using and Maintaining a Vacuum Cleaner' and the fifth (Dirt Pareeting) to 'The Dirt Inside the Vacuum Cleaner.'

\section{Conclusion}

The findings reported in this paper address the relationship between users' experiences of dirt and design interventions that could increase the longevity of vacuum cleaners. They form part of a UK Government-funded study on the repair and maintenance of vacuum cleaners.

The stakeholder interviews revealed that vacuum cleaner manufacturers develop new products and create sales by engaging with the sense of satisfaction and enjoyment that people gain by extracting dirt from their homes. The co-creation exercise demonstrated that consumers want an enjoyable experience of dirt removal and that features in new designs that appear likely to improve experiences could help drive new purchases, while the presence or visibility of dirt may encourage premature disposal. The product teardowns showed that cost-driven processes may result in machines that are more likely to be functionally and visually damaged in use, contributing to shorter product lifetimes. Both the product teardowns and consumer interviews confirmed survey evidence that vacuum cleaners are often discarded though still functional. Collectively, this illustrates that many vacuum cleaners are discarded not because they are broken beyond-repair, but because users perceive a loss of efficiency or face barriers to maintenance and repair, and replacement by pristine machines with new features is affordable.

sing Vassaurd et al.'s classification of cleaner types, evidence from our surveys indicated that Caring and Manic cleaners, who vacuum more often and give a high priority to cleanliness in their home, typically spend more on vacuum cleaners, replace their machines after a shorter period and are more likely to prefer their vacuum cleaner to look new, compared with Spartan and Minimal cleaners. Maintenance levels were low across all cleaner types, but Caring and Manic cleaners were more likely to undertake maintenance tasks. Motivations for disposal across cleaner types were similar, and we found no evidence that Caring and Manic cleaners' machines were being disposed of earlier than those of the other cleaner types because they had been used more frequently.

The priority put on home cleanliness relates, to some extent, to attitudes to the environment, with respondents willing to do 'a lot more' to help the environment significantly more likely to strongly agree that 'it's really important to me that I keep the floors in my home spotlessly clean.' Caring and Manic cleaners accounted for $60 \%$ of respondents in the first survey and $63 \%$ in the second; a potentially substantial share of the market. Together, the findings suggest that Caring and Manic cleaners should be targeted in any strategy to increase vacuum longevity. For Caring and Manic cleaners, the five preferred features from all the concepts illustrate underlying concerns of not being able to maintain their machines such that they remove dirt effectively and their desire to avoid contact with dirt. 
In conclusion, we propose the following five recommendations to increase vacuum longevity through design interventions and sugges that these be targeted at Caring and Manic cleaners. From the firs online survey and the co-creation stages these are: 1 . Design vacuums that will remain enjoyable to use over their lifetime; 2 . Design vacuums that are likely to retain an 'as new' aesthetic for as long as possible (e.g. by removing superfluous detailing). From the second online survey: 3 . Improve ease of machine maintenance to tackle real and perceived ineffectiveness as the machine ages; 4 . Reduce contact with dirt during maintenance tasks; 5 . Incorporate performance information to indicate when maintenance is required, to aid cleaning satisfaction and reassurance of the machine's ability to remove dirt.

There has hitherto been little research undertaken on the maintenance and use of consumer durables such as vacuum cleaners, despite the growing significance of product life extension strategies for progress towards a circular economy. In order to understand the effectiveness of the recommendations, a longitudinal study is suggested to trial design interventions on modified or prototype vacuums. Additionally, new business models for vacuum cleaner manufacturers require development (e.g. vacuum trade in and resale to other cleaner types) in order to understand how to make vacuum cleaner longevity attractive. Finally, the overall approach used in this project may have application in identifying effective strategies for decreasing the environmental impact and increasing the longevity of other products. Identifying and clustering users based on their current practices and environmental attitudes could help identify and focus effective design interventions and strategies for increasing product longevity.

\section{Acknowledgments}

The research presented in this paper was undertaken through a project funded by Defra's Action-Based Research Programme (reference no. EV0554)

\section{Appendix A. Supplementary data} Appendix A. Supplementary data
Supplementary data to this article can be found online at https: $/$
doi.org/10.1016/j.jclepro. 2019.04 .101 .

\section{References}

Allwood, J.M., Cullen, J.M., Carruth, M.A., Cooper, D.R., McBrien, R.L., Moynihan, M.C., Patel, A.C.H., 2012. Sustainable Materials with Both Open. UIT Cambridge, Cambridge. ba, S., Ardente, F., Mathieux, F., 2015. Technical Support for Environmental Footprinting, Material Efficiency in Product Policy and the European Platform on LCA - Durability Assessment of Vacuum Cleaners. JCR Science and Policy Report. Publications Office of the European Union, Luxembourg.

Bakker, C., Wang, F., Huisman, J., den Hollander, M., 2014. P exploring product life extension through design. J. Brook Lyndhurst, 2011. Public Understanding of Product Lifetimes and Durability: A Research Report Completed for the Department for Environment. Food and Rural Affairs. Department for Environment, Food and Rural Affairs, London.

Campbell, C. 1992. The desire for the new. In: Sitverstone. R., Hisch, E. (Eds.), Consuming Technologies: Media and Information in Domestic Spaces. Routledge,

Churchill Jr., G.A., Surprenant, C., 1982. Anvinkestigation into the determinants of customer satisfaction. J. Mark. Res. 19, 491-50

Cooper, T., Fisher, T., Harmer, L., Salvia, G., Barr, C., 2016. Dirt, damage, servicing and repair: understanding motivations for preduct disposal. London. Technical re-
and and repair: understanding motivations for product disposal. London. port for Defra http://randd.defra-gov.uk/Default. aspx?Me

Module $=$ ProjectList $\&$ Completed $=0 \&$ Contractor $I D=2195$.
Cooper, T., 2004. Inadequate life? Evidence of consumer attitudes to product obso-

lescence. J. Consum. Policy 27, 421-449.

Cooper, T., Mayers, K., 2000. Prospects for Household Appliances. Urban Mines, Halifax.

Design Council, 2006. Double Diamond Design Process. Design Council, London.
Dant, T., Bowles, D., 2003. Dealing with dirt: servicing and repairing cars. Socio. Res. Online 8, 1-17.

Denscombe, M. 2014. The Good Research Guide: for Small-Scale Social Research Projects. McGraw-Hill Education, New York, NY.

Douglas, M., 1966. Purity and Danger. Routledge \& Kegan Paul, Lond

Fisher, T., Cooper, T., Harmer, L., Salvia, G., Barr, C., 2015. The pelationshịp betwee ideas about cleanliness and actions that affect product longevity In: Cooper, $\mathrm{T}$ Braithwaite, N., Moreno, M., Salvia, G. (Eds.), Product Lifetimes and the Environment (PLATE). Nottingham Trent University, CADBE, pp. 119-125.

Fisher, T., Shipton, J., 2009. Designing for Re-use: the Life of Consumer Packaging Routledge, London.

Fisher, T.H., 2004. What we touch, touches us: materials, affects, and affordances. Des. Issues 20, 20-31.

Forty, A., 1986. Objects of Desire: Designs and Society 1750-1980. Thames and Hudson, London.

Gallego-Schmid, A., Mendoza, J.M.F., Jeswani, H.K. Azapagic,A., 2016. Life cycle environmental impacts of vacuum cleaners and the effects of European regulation. Sci. Total Environ. 559, 192-203.

Gnanapragasam, A., Cole, C., Singh, J., Cooper, T 2018. Consumer perspectives on longevity and reliability: a national study of purchasing factors across eighteen product categories. Procedia CIRP 69, 910 915.

Harmer, L., Cooper, T., Fisher, T., Salvia, G., Bare, C., 2015. The joy of vacuuming? How the user experience affects vacuum cleaner longevity. In: Cooper, T., BraithThe (PLATE). Nottingham Trent University, CADBE, pp. 138-146.

HM Government, 2013. Prevention Is Better than Cure: the Role of Waste Prevention in Moving to a More Resource Efficient Economy. HM Government, London.

Health and Safety Executive (HSE) 2018. Waste electrical and electronic equipmen recycling (WEEE). In: http://www.hse.gov.uk/waste/waste-electrical.htm, Accessed 12 November 2018

Institution of Civil Engineers (ICE), 1955. Obituary. Hubert Cecil Booth. 1871-1955. vol. 4, Thomas Telford-ICE Virtual Library, 631-632, (4) https://doi.org/10.1680 iicep. 19551 1412Accessed 6 November 2019

Jackson, S., 1992. January. Towards a historical sociology of housework: a materialis feminist analysis. Wom Stud. Int. Forum 15, 153-172.

Kemmis, S.McTaggart, R., Nixon, R., 2013. The Action Research Planner: Doing Critieal Rarticipatory Action Research. Springer Science \& Business Media, Singapore.

gerspetz, O., 2018. A Philosophy of Dirt. Reaktion Books. Padstow. TJ Inter-

national.

NTEL, 2010 Vacuum cleaners UK. In: http://reports.mintel.com/display/479873/, November 2015 .

a. Electrical goods retailing. In: http://reports.mintel.com/display/ 655752/, Accessed 15 November 2015 .

TEt 2013b. Household cleaning equipment. In https://store mintel.com/ sehold-cleaning-equipment-uk-june-2013/, Accessed 20 November 2015.

-Belis, V., Bakker, C., Juan, P., Bovea, M.D., 2017. Environmental performance of alternative end-of-life scenarios for electrical and electronic equipment: a case study for vacuum cleaners. J. Clean. Prod. 159, 158-170.

Pierides, D., Woodman, D., 2012. Object-oriented sociology and organizing in the face of emergency: bruno Latour, Graham Harman and the material turn. Br. J. Sociol. $63,662-679$.

Robson, C., 2011. Real World Research, third ed. Wiley, Chichester.

Rozin, P., Haidt, J., McCauley, C.R., 1993. Disgust. In: Lewis, M., Haviland, J.M. (Eds.), Handbook of Emotions. N.Y Guilford Press, New York, pp. 575-594.

Salvia, G., Cooper, T., Fisher, T., Harmer, L., Barr, C., 2015. What is broken? Expected lifetime, perception of brokenness and attitude towards maintenance and repair. In: Cooper, T., Braithwaite, N., Moreno, M., Salvia, G. (Eds.), Product Lifetimes and the Environment (PLATE). Nottingham Trent University, CADBE, pp. $342-349$.

Sanders, E.B.-N., Stappers, P.J., 2008. Co-creation and the New Landscapes of Design, vol. 4 , Co-design, $5-18$

Schifferstein, H.N.J., Zwartkruis-Pelgrim, E.P.H., 2008. Consumer-product attachment: measurement and design implications. Int. J. Des. 2, 1-13.

Statista, 2018. Number of people purchasing vacuum cleaners in the United Kingdom (UK) from 2016 to 2017, by expenditure (in 1,000s). In: Statista - the Statistics Portal. https://www.statista.com/statistics/303101/standard-vacuum-cleaner-userexpenditure-in-the-uk/Accessed 25 March 2019

Stoppani, T., 2011. Dust, vacuum cleaners, (war) machines and the disappearance of the interior. IDEA J. 50-59.

Vaussard, F., Fink, J., Bauwens, V., Rétornaz, P., Hamel, D., Dillenbourg, P., Mondada, F., 2014. Lessons learned from robotic vacuum cleaners entering the hom ecosystem. Robot. Autonom. Syst. 62, 376-391.

Which, 2014a. Repair or replace?. In: https://conversation.which.co.uk/home-energy/ repair-or-replace-appliances-debate/, Accessed 10 November 2015. 
Which, 2014b. Vacuum cleaners. In: https://www.which.co.uk/news/2014/12/top-5popular-vacuums-of-2014-on-which-co-uk-386731/, Accessed 21 November 2015. Which, 2017a. Are vacuum cleaners as good as they used to be?. In: https://www. which, 2017a. Are vacuum cleaners as good as they used to be?. In: https://www.
which.co.uk/news/2017/10/are-vacuum-cleaners-as-good-as-they-used-to-be/, Ac-

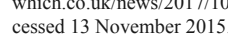

Which, 2017b. Are vacuum cleaners as good as they used to be?. In: https://www

which.co.uk/news/2017/10/are-vacuum-cleaners-as-good-as-they-used-to-be/, Ac-
cessed 13 November 2017
WRAP, 2013a. Electrical and electronic product design: product lifetime. In: http:/ www.wrap.org.uk/sustainable-electricals/esap/consumer-behaviour/reports/ consumer-research-electrical-product-lifetimes, Accessed 1 November 2015 WRAP, 2013b. Switched on to value. In: http://www.wrap.org.uk/sites/files/wrap/ Switched $\% 20$ on $\% 20$ to\%20Value\%2012\%202014.pdf, Accessed 1 November

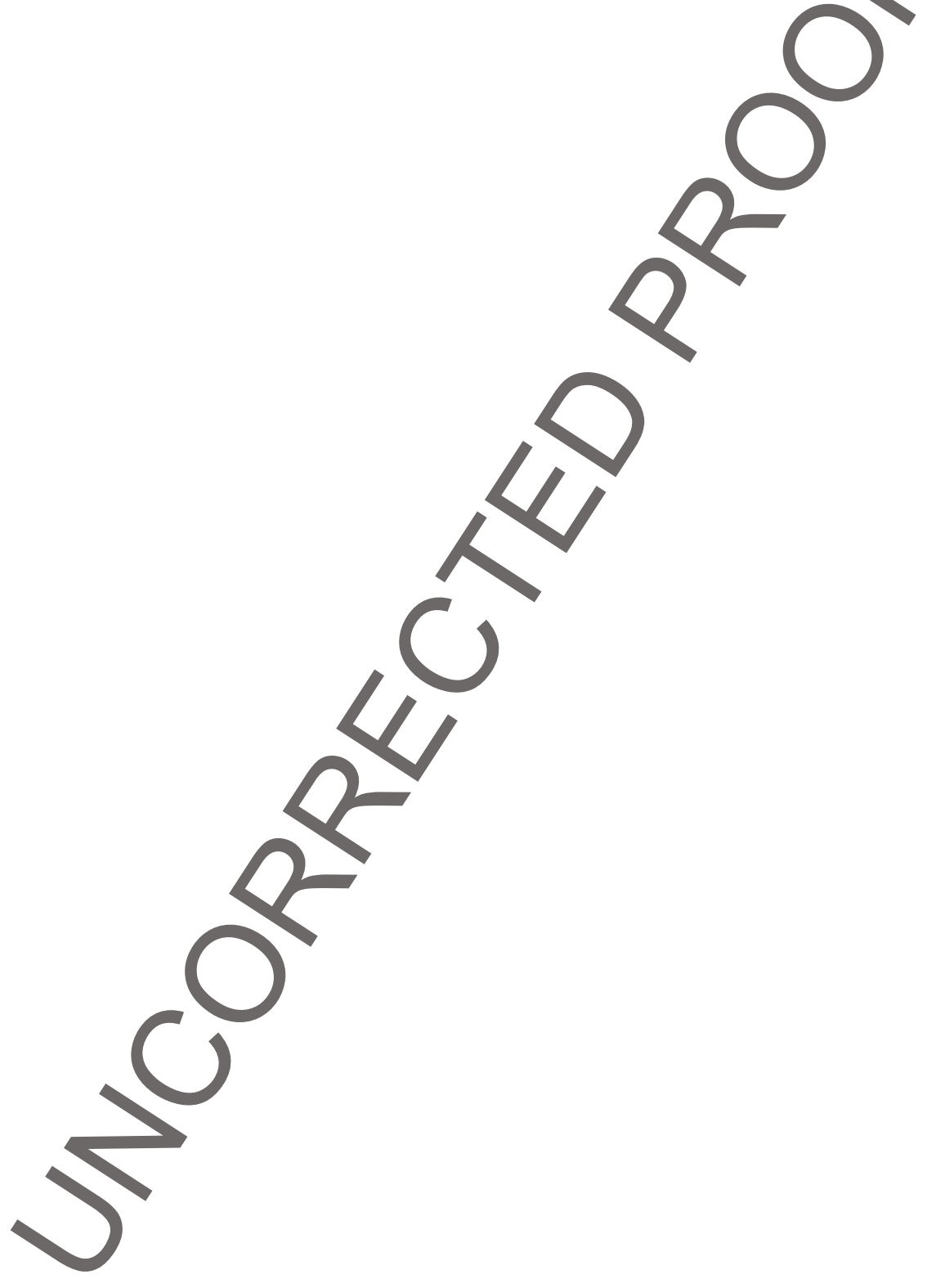

